\title{
Phase I study of intraventricular recombinant tissue plasminogen activator for treatment of posthaemorrhagic hydrocephalus
}

\author{
Andrew Whitelaw, Elie Saliba, Vineta Fellman, Marie-Christine Mowinckel, Dominique \\ Acolet, Neil Marlow
}

\section{Department of Paediatrics, Aker Hospital, University of Oslo, 0514 Oslo, 5 Norway \\ Andrew Whitelaw}

Haematology Research Laboratory

Marie-Christine

Mowinckel

Neonatology

Department,

Clocheville Unniversity

Hospital,

University of Tours,

France

Elie Saliba

Children's Hospital, University of Helsinki, Helsinki, Finland

Vineta Fellman

Department of Paediatrics,

Hillingdon Hospital,

Middlesex

Dominique Acolet

Department of Child Health,

St Michael's Hospital,

University of Bristol

Neil Marlow

Correspondence to: Professor A Whitelaw.

Accepted 15 February 1996

\begin{abstract}
Aim-Phase I study to evaluate intraventricular fibrinolytic treatment with recombinant tissue plasminogen activator (tPA) as a method of clearing blood from the cerebrospinal fluid, and thus preventing permanent hydrocephalus.

Methods- Twenty two preterm infants, aged 7 to 26 days, with progressive posthaemorrhagic ventricular dilatation (ventricular width $>4 \mathrm{~mm}$ over 97 th centile) received one to five intraventricular bolus injections of $1.0 \mathrm{mg}$ or $0.5 \mathrm{mg}$ tPA at intervals of one to seven days.

Results-The mean cerebrospinal fluid concentration of tPA 24 hours after $1 \mathrm{mg}$ was $1860 \mu \mathrm{g} / \mathrm{ml}$. The half life of tPA in cerebrospinal fluid was about 24 hours. Twenty one (95\%) infants survived, 12 (55\%) without shunt surgery. One infant had secondary intraventricular haemorrhage.

Conclusion-Intraventricular tPA resulted in survival without a shunt for most of the infants, but with some risk. Failure may have been due to plasminogen deficiency, an inhibitor, or late intervention. (Arch Dis Child 1996;75:F20-F26)
\end{abstract}

Keywords: tissue plasminogen activator, hydrocephalus, cerebrospinal fluid, intraventricular treatment.

The past 15 years have seen extensive research in the aetiology and prophylaxis of intraventricular haemorrhage (IVH) in preterm infants. ${ }^{1}$ Many neonatal centres have experienced a reduction in the incidence of IVH. Nevertheless, we lack safe and effective treatment for its most serious direct complication, posthaemorrhagic hydrocephalus (PHH). Early ventriculo-peritoneal shunting has a high rate of blockage, infection, and skin ulceration. ${ }^{2}$ External ventricular drainage has a high rate of infection in most centres. Early treatment with repeated lumbar or ventricular punctures has not been shown to reduce the need for shunts, or to improve neurological outcome ${ }^{3-5}$; and repeated tapping has a $7 \%$ risk of infection. ${ }^{5}$ Drugs to reduce the production of cerebrospinal fluid have side effects and have not been shown to improve outcome. ${ }^{6} 7$

Hill et al hypothesised that the initial phase of PHH was caused by multiple small blood clots which obstructed the arachnoid villi, the main sites of reabsorption of cerebrospinal fluid. ${ }^{8}$ This being so, there should be a period of time during which $\mathrm{PHH}$ is potentially reversible if the blood clots can be cleared before chronic arachnoiditis in the basal cisterns renders the hydrocephalus permanent. ${ }^{9}$ There is evidence of endogenous fibrinolytic activity in cerebrospinal fluid about 18 days after IVH, which continues for many weeks. ${ }^{10}$ Posthaemorrhagic cerebrospinal fluid contains high concentrations of fibrin degradation products, ${ }^{11}$ and tissue plasminogen activator (tPA) is present in posthaemorrhagic cerebrospinal fluid. ${ }^{12}$ Two animal models of PHH (dogs and cats) have shown that intraventricular urokinase ${ }^{13}$ or intracisternal tPA, ${ }^{14}$ starting within 24 hours of the injection of blood, can significantly reduce the risk of subsequent hydrocephalus. Recombinant human tPA has been quite widely used intrathecally as part of the management of subarachnoid haemorrhage after surgery for aneurysm. ${ }^{15-18}$ Intraventricular tPA has been used with apparent success in adults with intraventricular haemorrhage, when combined with ventricular drainage. ${ }^{19-21}$

Our first pilot study of intraventricular fibrinolytic treatment, in infants who were just beginning to develop $\mathrm{PHH}$, involved the use of streptokinase. We chose streptokinase because Stewart had previously shown that it could safely be given in intraventricular mode to infants, because of its relatively low cost and because, ${ }^{22}$ at that time (1990), there was no published evidence that tPA could be given safely into the cerebrospinal fluid. The first nine infants showed encouraging results, ${ }^{23}$ but this was not sustained and of 13 infants treated, one died early and four became shunt dependent. The antigenicity of streptokinase and the unknown potential for stimulating an immune reaction in the brain, together with its reduced specificity for fibrin, ${ }^{24}$ were factors making us reconsider our choice of fibrinolytic agent in 1992. Furthermore, streptokinase requires a higher concentration of plasminogen to be effective, compared with tPA, and cerebrospinal fluid plasminogen concentrations are much lower than those found in plasma. ${ }^{25}$ We now report a phase I study of intraventricular tPA to evaluate its potential in the prevention of permanent posthaemorrhagic hydrocephalus in preterm infants.

\section{Methods}

\section{ELIGIBILITY}

Infants were eligible for the study if they met the following criteria:

(i) Intraventricular haemorrhage documented by ultrasound scan 
(ii) Progressive expansion of ventricular width

(iii) The smaller ventricular width exceeding 4 $\mathrm{mm}$ over the 97 th centile of Levene ${ }^{26}$

(iv) No more than 28 days elapsed since the estimated date of the haemorrhage

(v) No systemic bleeding tendency

(vi) Parental consent to treatment with tPA

Ventricular width was measured in the midcoronal view from the midline to the lateral border of each lateral ventricle. The criteria are the same as those used in the large multicentre trial of early tapping for posthaemorrhagic ventricular dilatation (PHVD) ${ }^{5}$ and are being used in the current randomised trial of acetazolamide and frusemide for PHVD (coordinator Dr Colin Kennedy, Department of Paediatrics, Southampton General Hospital, England). These inclusion criteria were chosen to be consistent with previous major trials in this condition, and because these criteria have identified infants with a $60 \%$ risk of permanent shunt dependence in survivors, and a high risk of cerebral palsy. ${ }^{5}$ Although earlier treatment might have been more effective, it might also have included more infants in whom PHVD would resolve spontaneously. It was felt that such a highly invasive treatment with potentially adverse effects should only be given to infants with a relatively poor prognosis with conventional management.

DOSE OF TPA

Table 1 shows the doses of tPA used. TPA (Actilyse, Boehringer Ingelheim International $\mathrm{GmbH}$, Ingelheim, Germany) was given as bolus intraventricular injections of $1.0 \mathrm{mg}$ to 21 of the infants, with $0.5 \mathrm{mg}$ being used in two infants because of concern over low plasma fibrinogen concentrations. The dose of $1 \mathrm{mg}$ was not chosen on the basis of body weight, but, rather, on the large amount of intraventricular blood clot present in some neonates. (1)Adults have received from $2 \mathrm{mg}$ to $15 \mathrm{mg}$ into the cerebrospinal fluid. ${ }^{14-21}$ Treatment was limited to five doses of tPA.

Table 1 Clinical characteristics and outcome in infants receiving intraventricular $t P A$

\begin{tabular}{lllllllll}
\hline $\begin{array}{l}\text { Case } \\
\text { No }\end{array}$ & Birthweight & $\begin{array}{l}\text { Gestational } \\
\text { age }\end{array}$ & $\begin{array}{l}\text { Age starting } \\
\text { tPA }\end{array}$ & Dose $(\mathrm{mg})$ & Catheter? Shunt? & Bleed? & Alive? \\
\hline 1 & 805 & 26 & 19 days & $1 \times 1$ & No & Yes & No & Yes \\
2 & 960 & 28 & 22 & $1 \times 1$ & No & Yes & No & Yes \\
3 & 1420 & 29 & 23 & $1 \times 2$ & No & No & No & Yes \\
4 & 1423 & 30 & 19 & $1 \times 2$ & No & No & No & Yes \\
5 & 1770 & 31 & 21 & $1 \times 2$ & No & Yes & No & Yes \\
6 & 1495 & 28 & 23 & $1 \times 2$ & No & Yes & No & Yes \\
7 & 1715 & 31 & 16 & $1 \times 2$ & No & No & No & Yes \\
8 & 1300 & 29 & 13 & $1 \times 2$ & No & No & No & Yes \\
9 & 2500 & 33 & 14 & $1 \times 2$ & No & Yes & Yes & Yes \\
10 & 1200 & 27 & 16 & $1 \times 2$ & No & Yes & No & Yes \\
11 & 1480 & 29 & 12 & $1 \times 4$ & No & No & No & Yes \\
12 & 815 & 26 & 13 & $1 \times 4$ & No & No & No & Yes \\
13 & 1010 & 27 & 14 & $1 \times 4$ & No & No & No & No \\
14 & 1500 & 29 & 23 & $1 \times 5$ & No & Yes & No & Yes \\
15 & 1178 & 27 & 13 & $1 \times 5$ & No & No & No & Yes \\
16 & 1370 & 32 & 8 & $1 \times 5$ & No & No & No & Yes \\
17 & 1100 & 30 & 9 & $1 \times 5$ & Drain & No & No & Yes \\
18 & 1300 & 26 & 26 & $1 \times 3$ & Drain & Yes & No & Yes \\
& & & & $0.5 \times 2$ & & & & \\
19 & 1100 & 26 & 26 & $1 \times 2$ & Drain & No & No & Yes \\
20 & 1300 & 30 & 13 & $1 \times 3$ & Drain & No & No & Yes \\
21 & 1020 & 26 & 11 & $0.5 \times 3$ & Drain & No & No & Yes \\
22 & 1340 & 28 & 14 & $1 \times 5$ & Drain & No & No & Yes \\
\hline
\end{tabular}

Bleed = secondary intraventricular haemorrhage.
DELIVERY OF TPA TO VENTRICLES

The means by which tPA was delivered to the ventricle varied from centre to centre, according to the availability of a paediatric neurosurgeon. Sixteen of the infants received tPA by ventricular puncture (by a neonatologist), usually with a 22 gauge spinal needle. Cerebrospinal fluid was allowed to drain out until the pressure returned to normal (about $4 \mathrm{~cm}$ water $)^{27}$ before each dose of IPA was given. In six cases a ventricular catheter was inserted by a paediatric neurosurgeon and connected to a closed external drainage system. The tPA was given with the catheter clamped distally for two hours before cerebrospinal fluid was allowed to drain continuously against a pressure of 3 to 6 $\mathrm{cm}$ of water. A lumbar puncture was carried out one to 24 hours after intraventricular injection of tPA. The purpose of this was to draw tPA through the ventricular system into the subarachnoid space, thus reaching the arachnoid villi.

Great care was taken with the sterile technique. Neither intraventricular nor intravenous antibiotic treatment was given routinely to cover percutaneous ventricular punctures.

\section{MONITORING}

Head circumference was measured daily and a cerebral ultrasound examination was carried out daily during tPA treatment and then twice weekly until discharge. Prothrombin time (or equivalent), cephalin-kaolin time and platelets were measured in peripheral blood before the start of tPA treatment. Plasma fibrinogen was measured daily during tPA treatment as an indication of systemic fibrinolysis. Contraindications to further doses of tPA were:

-persistently diminishing ventricular size after the previous dose of tPA (successful treatment) -evidence of fresh intraventricular haemorrhage

-evidence of a systemic fibrinolytic effect with plasma fibrinogen $0.5 \mathrm{~g} / 1$ or less

-concern about the infant's general condition-for example, suspicion of infection

ENDPOINTS AND SAMPLE SIZE

The objective of tPA treatment was survival without the need for shunt surgery. Thus the need for shunt surgery was a major endpoint, as was death before discharge from hospital. The indication for shunt surgery was progressive head expansion with raised intracranial pressure, despite medical treatment, or the need for repeated cerebrospinal fluid tapping for more than six weeks to control expansion or pressure. Because infants occasionally develop late progressive hydrocephalus, we waited until at least nine months postnatally before reporting that an infant had survived without a shunt. A further endpoint was secondary intraventricular haemorrhage during tPA treatment. Although the study was not a randomised trial, we planned to make a comparison with the results of the Ventriculomegaly Trial of Early Cerebrospinal Fluid Tapping, ${ }^{5}$ which had identical inclusion criteria, and a minimum sample size of 20 was planned. We had hoped that intraventricular shunting would halve the 

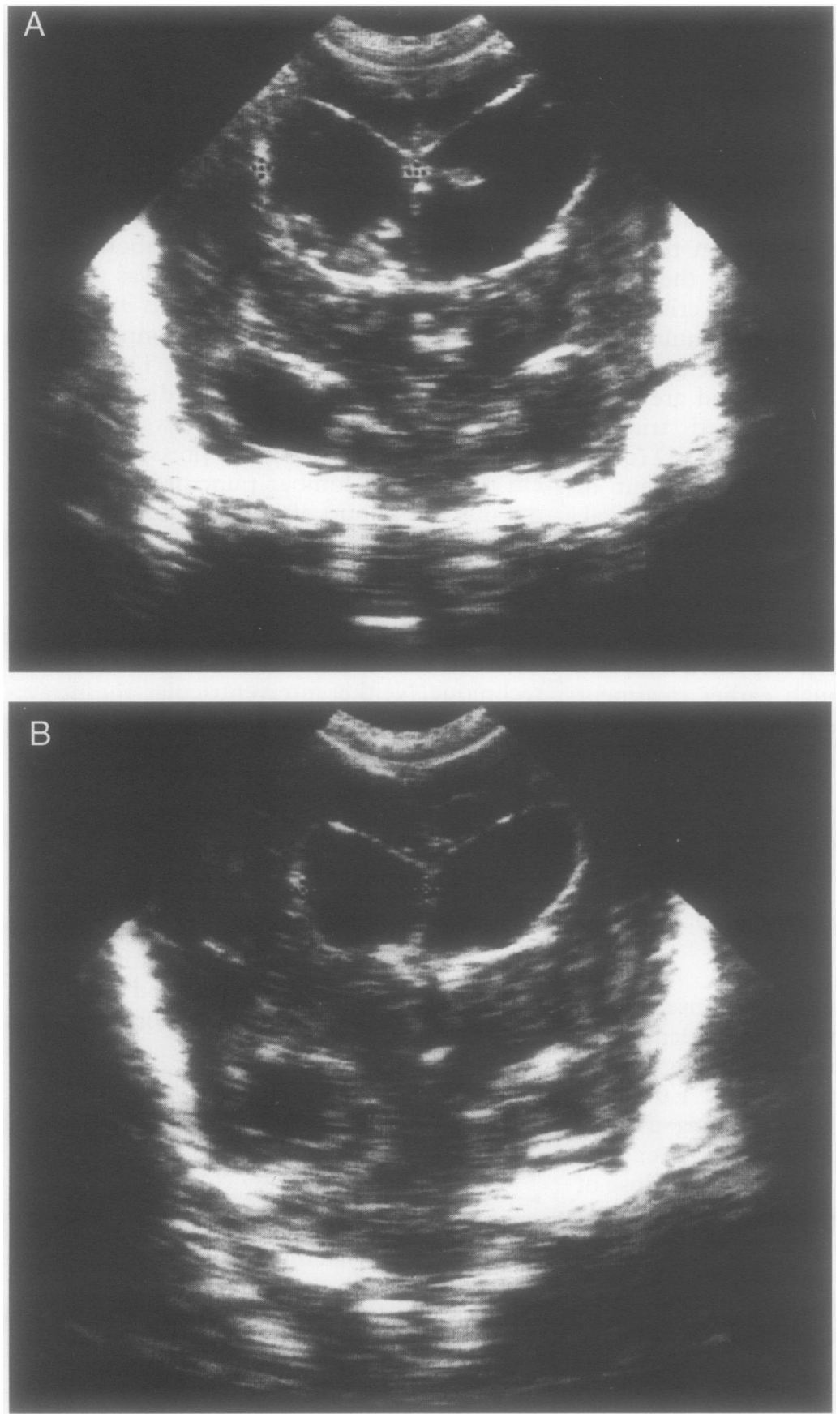

Figure 1 Mid-coronal cerebral ultrasound scans from case 3. Scan $1 A$ was taken before tPA treatment and shows bilateral ventricular dilatation with blood clots visible within both lateral ventricles. Scan $1 B$ was taken seven days later (after two doses of tPA). The intraventricular clots can no longer be seen and the ventricular system has become smaller. tPA would lead to a halving in the proportion of infants dying or surviving with a permanent shunt. purposes of obtaining pharmacokinetic information. Eight cerebrospinal fluid samples taken 24 hours after the injection of $1 \mathrm{mg}$ tPA were analysed for tPA antigen. In one infant we were able to analyse seven daily ventricular cerebrospinal fluid samples obtained for clinical indications after a single intraventricular dose of $1 \mathrm{mg}$ tPA. In two other infants (on three occasions) we were able to examine two sequential ventricular cerebrospinal fluid samples after $1 \mathrm{mg}$ tPA. This allowed us to examine the clearance of exogenous tPA from the cerebrospinal fluid using the same ELISA technique.

This study was approved by the Norwegian Medicines Control Authority and the local Research Ethics Committees. Informed consent to tPA treatment was obtained from the parents of each infant.

\section{Results}

Table 1 shows the characteristics of the 22 preterm infants who entered the study. Median birthweight was $1300 \mathrm{~g}$ (range 805-2500 g). Median gestation was 28.5 weeks (range 26-33). Using Papile's classification, ${ }^{29} 14$ had grade 3 IVH and eight had grade 4 IVH. Nineteen had had respiratory distress syndrome treated with mechanical ventilation and surfactant. Two had had confirmed septicaemia. Three had had persistent pulmonary hypertension. Three had had birth asphyxia. Median age at diagnosis of IVH was 2 days (range 0-6 days). The median age at which the infant reached treatment criteria was 12 days ( range 6-26 days). The median age at start of treatment was 15 days ( range 8-26 days). Two infants received one dose, nine received two doses, two received three doses, three received four doses and six received five doses. The median dose interval was two days and the range was one to seven days.

\section{CLINICAL OUTCOME}

Table 1 also shows the principal outcomes in the 22 infants. Twelve survived and have returned home without shunt surgery. Nine infants have been shunted and survived. One died (this infant was not shunted, had severe periventricular leucomalacia, and died of respiratory failure with unresolved hydrocephalus). The minimum length of follow up was nine months at the time of writing. When comparing infants with adverse outcomes with those with successful outcomes, there was no significant difference in birthweight, grade of IVH, or age on starting treatment. No infant developed ventriculitis during tPA treatment.

\section{PHARMACOKINETIC STUDY}

TPA is estimated to have a plasma half life of three to eight minutes. ${ }^{24}{ }^{28} \mathrm{Had}$ this been the case in cerebrospinal fluid, it would have been necessary to give a continuous infusion of tPA to obtain a prolonged effect. We have already shown that tPA antigen can be demonstrated in cerebrospinal fluid in infants with PHVD, using an ELISA technique (Biopool TintElize tPA, Biopool AB, Umeå, Sweden).${ }^{12}$ For ethical reasons, it was not possible to give intraventricular tPA and take repeated timed samples of ventricular cerebrospinal fluid purely for the
DISAPPEARANCE OF CLOTS ON ULTRASOUND SCAN Figure 1 shows case 3 with ventricular dilatation and intraventricular blood clot bilaterally. Seven days later (after two doses of tPA) the intraventricular clots were no longer visible and the ventricular width had decreased from $21.5 \mathrm{~mm}$ to $17.0 \mathrm{~mm}$. Figure 2 shows case 15 with a large intraventricular clot before and 11 days after starting tPA treatment. Despite the high concentrations of tPA in the ventricular cerebrospinal fluid, there was virtually no 
decrease in the size of the clot. Figure 3 shows case 16 before, six, 14 and 25 days after starting tPA treatment. There was a gradual decrease in the size and eventual disappearance of the intraventricular clot, but the infant went on to develop permanent hydrocephalus and became shunt dependent.

\section{ADVERSE EFFECTS OF INTRAVENTRICULAR TPA Intraventricular rebleeding}

One infant (case 9) had clinical evidence of intraventricular bleeding during tPA treatment. The infant became pale and lethargic, with a bulging fontanelle, about 16 hours after the second dose of tPA. Figure 4 shows the lateral ventricles distended with diffuse echogenic blood which had not been present a few days before. Blood was aspirated from the ventricle to normalise intracranial pressure; $10 \mathrm{mg} / \mathrm{kg}$ tranexamic acid (Cyklokapron, Kabi Pharmacia) was immediately given intravenously to inhibit plasmin, and a blood transfusion was started. The infant stabilised within a few hours. She subsequently had a ventriculoperitoneal shunt operation, and had mild motor delay with increased tone on the right side 12 months after birth (fig 4).

\section{Systemic fibrinolysis}

Plasma fibrinogen before tPA treatment was mean 2.28(SD 1.14) g/l. The lowest plasma fibrinogen concentrations during tPA treatment were $2.04(1.90) \mathrm{g} / \mathrm{l}$. In two infants (cases 7 and 19) the plasma fibrinogen fell from over $1.0 \mathrm{~g} / 1$ to $0.5 \mathrm{~g} / 1$ and $0.28 \mathrm{~g} / 1$, respectively, recovering after three and five days. In three other infants plasma fibrinogen fell transiently to $0.8,0.9$ and $0.98 \mathrm{~g} / \mathrm{l}$. There was no clinically evident systemic bleeding tendency in any infant.

CEREBROSPINAL FLUID CONCENTRATIONS OF TPA Ventricular cerebrospinal fluid samples 24 hours after bolus administration of $1 \mathrm{mg}$ of intraventricular tPA in eight infants showed concentrations ranging from 870 to $2907 \mu \mathrm{g} / 1$ with a mean (SD) of $1860(841) \mu \mathrm{g} / \mathrm{l}$. Figure 5 shows the serial cerebrospinal fluid tPA concentrations after the intraventricular administration of $1 \mathrm{mg} \mathrm{tPA}$ in case 10 . There is almost an exponential decline in tPA after two days and the data indicate that the terminal cerebrospinal fluid half life of tPA is about 24 hours, ${ }^{30}$ assuming a two compartment model. The repeated measurements of cerebrospinal fluid tPA in the other two infants also showed a half life of about 24 hours.

\section{Discussion}

A phase I trial of a new treatment examines: evidence that the intended therapeutic effect is being achieved; the practicality of administering the new treatment; pharmacokinetics; and adverse effects. No intervention has been shown in a randomised trial to improve outcome in PHVD and different centres have adopted different approaches, some being very conservative and others more interventionist with the early use of a ventricular drain or reservoir. Our study had to be carried out as a

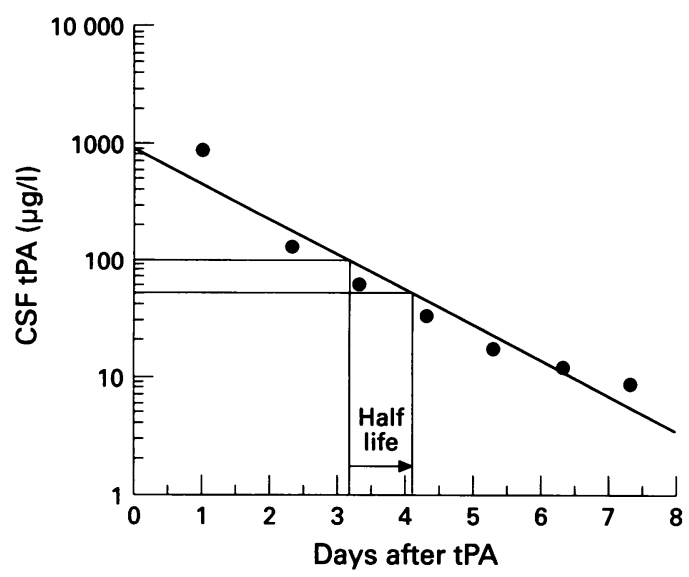

Figure 5 Ventricular cerebrospinal fluid concentrations of tPA following a single intraventricular injection of $1 \mathrm{mg}$ tPA (case 10). The diagonal line is an exponential plot; the vertical and horizontal lines indicate the terminal half life (the concentration halving from 100 to $50 \mu \mathrm{g} / \mathrm{l}$ ).

multicentre study because of the rarity of PHVD and thus it was inevitable that the "standard treatment" at each centre would vary. As no treatment has been shown to be superior to another, we do not think that is a major fault in our study. The experimental intervention, therefore, was the addition of intraventricular tPA to the existing treatment in each department.

\section{THERAPEUTIC EFFECT}

When evaluating a radically new treatment with potentially serious adverse effects and unknown pharmacokinetics in a rare condition, it would have been inappropriate to conduct a randomised trial, which, to be of sufficient power, would have required at least 150 infants. We therefore conducted this pilot study to give an approximation of the practical problems, the pharmacokinetics (and therefore doses), adverse effects and whether the treatment looks promising enough to proceed to a more ambitious trial. Furthermore, as a large group of 157 carefully documented infants with PHVD and identical inclusion criteria had been reported before, ${ }^{5}$ so it was natural to compare our tPA treated infants with the infants in the Ventriculomegaly Trial, acknowledging that many aspects of neonatal care have changed between 1984 and 1993. Forty five per cent of the tPA treated infants were shunted or died. This compares with $71 \%$ being shunted or dying in the Ventriculomegaly Trial $^{5}\left(P<0.02 ; \chi^{2}\right.$ test $)$. Despite this significant result, we must be very careful not to rely too much on a comparison of two groups of infants separated by so many years. Furthermore, we emphasise that our target of halving the proportion of infants who died or were shunted was not reached.

\section{RISK OF SECONDARY HAEMORRHAGE}

Fibrinolytic treatment has always been associated with concern about secondary haemorrhage and this complication occurred in one $(4.5 \%)$ of the infants in our study. Fortunately, the infant recovered with prompt treatment. Nevertheless, such a complication is highly undesirable. The mechanism of secondary 

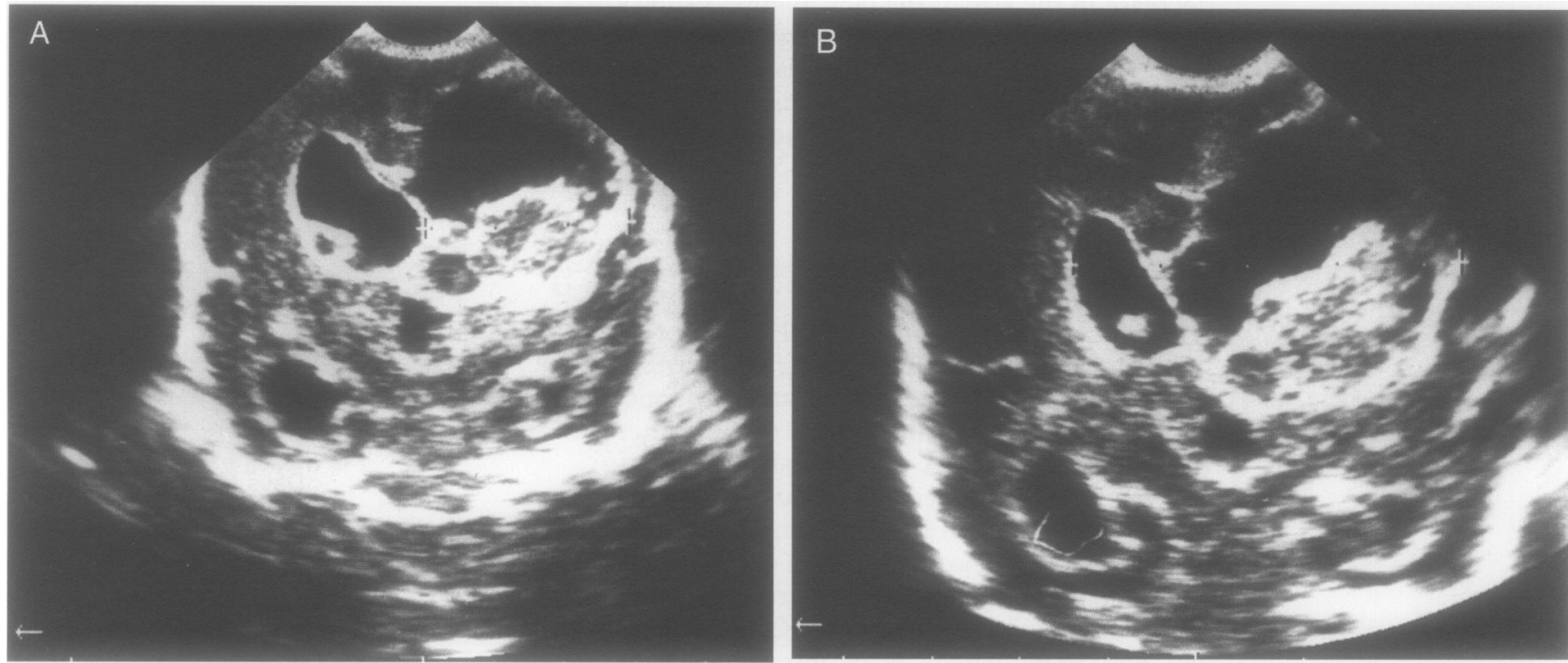

Figure 2 Mid-coronal cerebral ultrasound scans (case 15). Scan $2 A$ was taken before tPA treatment started. There is a large (white) clot in the right lateral ventricle and a small clot in the left lateral ventricle. Both lateral ventricles are dilated as is the third ventricle. Scan $2 B$ is a corresponding scan 11 days after starting $t P A$ treatment. There was virtually no reduction in the amount of intraventricular clot.
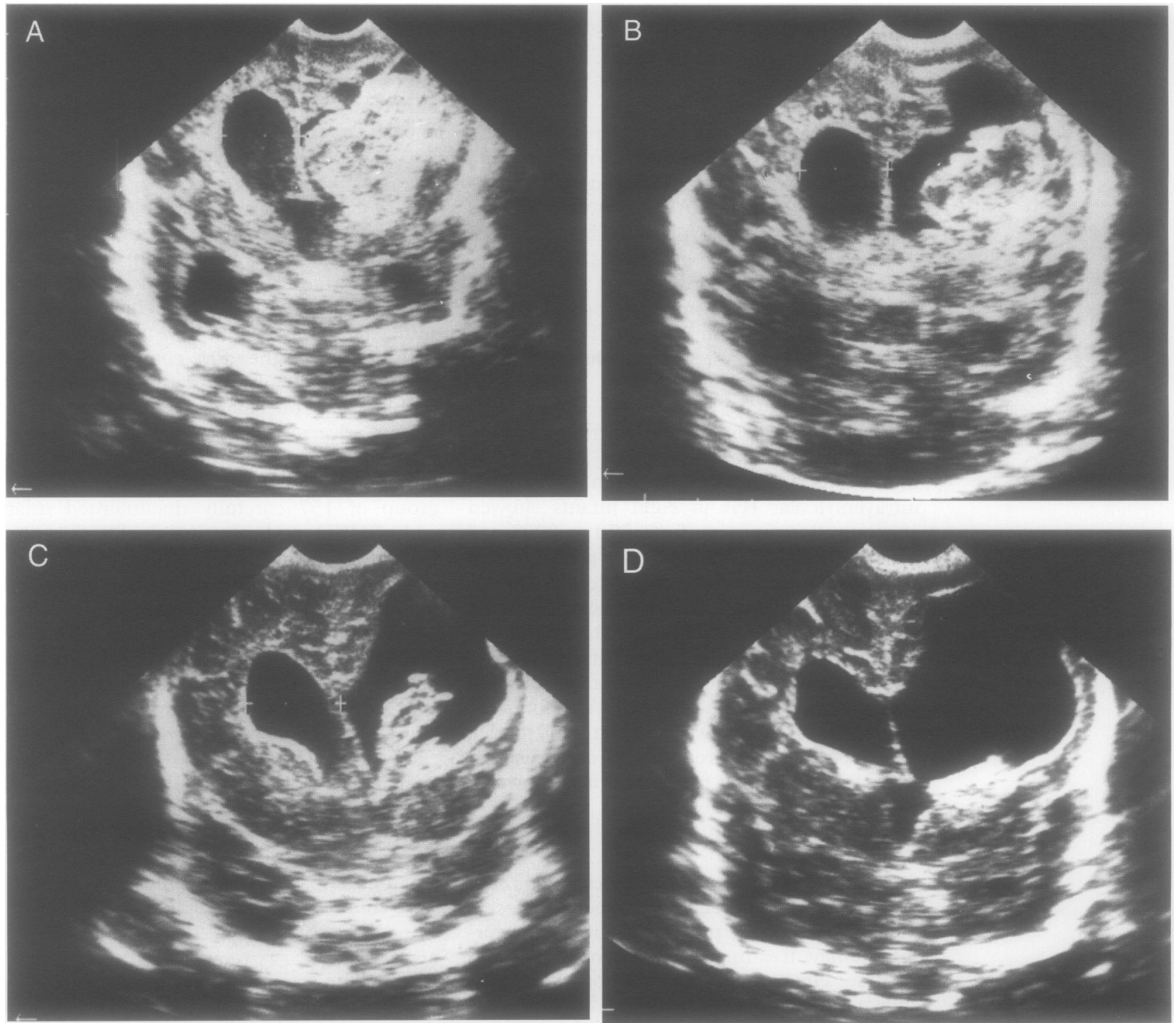

Figure 3 Mid-coronal cerebral ultrasound scan (case16). Scan $3 A$ was taken before the start of $t P A$. There is a large (white) clot in the right lateral ventricle as well as bilateral dilatation and a porencephalic cyst. Scan $3 B$ was taken six days after starting $t P A$ treatment. There is a moderate reduction in the amount of intraventricular clot. Scan 3C, taken 14 days after starting tPA, shows a further reduction in the amount of intraventricular blood clot. Scan $3 D$ is a corresponding scan 25 days after $t P A$ treatment was started. The intraventricular clot has completely disappeared, but the ventricular system is still dilated. 

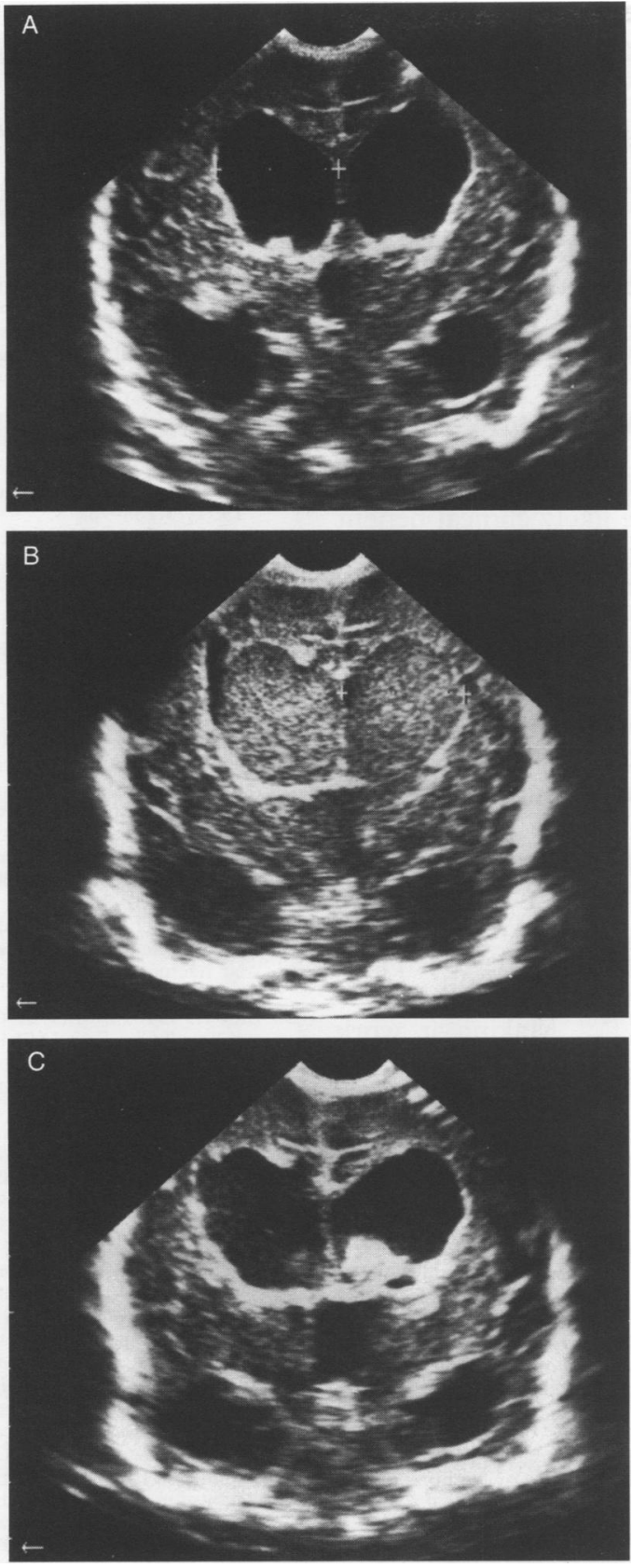

Figure 4 Mid-coronal cerebral ultrasound scans from case 9. Scan $4 A$ was taken after the first dose of tPA, showing bilateral ventricular dilatation with relatively echolucent cerebrospinal fluid. Scan $4 B$ was taken 16 hours after the second dose of $t P A$. The ventricular system is more distended and has become full of diffuse echogenicity (blood). Scan $4 C$ was taken six days after the second dose of $t P A$ and shows a smaller solid clot within the right lateral ventricle.

intraventricular haemorrhage may be that a fibrin plug is removed from the original ependymal bleeding site over the germinal matrix. Local trauma may also be a contributing factor, although no fresh blood was seen at the time of ventricular puncture.

PHARMACOKINETICS IN CEREBROSPINAL FLUID The direct injection of tPA into the cerebral ventricles achieves tPA concentrations, 24 hours later, about 1000 times the endogenous concentration of tPA in the cerebrospinal fluid of infants with PHVD. ${ }^{12}$ Such concentrations are comparable with those found to be thrombolytic in the treatment of coronary artery thrombosis. ${ }^{28}$ The half life of tPA in the cerebrospinal fluid is about 24 hours, very much longer than the plasma half life of three to eight minutes. ${ }^{24}{ }^{28}$ Thus it is clearly not necessary to give intraventricular tPA as a continuous infusion. A dosing interval of between one and two days should maintain the cerebrospinal fluid tPA concentration at around $500-1000 \mu \mathrm{g} / 1$. The cerebrospinal fluid tPA analyses reported here were made in infants treated only by ventricular puncture and the pharmacokinetics would be expected to be different in infants with a ventricular drain. We presume that the enzyme systems for metabolising tPA are virtually non-existent in the cerebrospinal fluid compartment, and very slow diffusion out of the cerebrospinal fluid accounts for the long half life. This slow process, combined with the rapid intravascular elimination of tPA, would be expected to reduce the risk of a systemic fibrinolytic effect. Nevertheless, two of the infants did develop hypofibrinogenaemia during tPA treatment, but without a clinical bleeding tendency. Impaired hepatic synthesis of fibrinogen (because of immaturity and previous illness) was probably a contributing factor.

POSSIBLE REASONS FOR LACK OF OPTIMAL THERAPEUTIC EFFECT

The treatment failed in a considerable proportion despite very high concentrations of tPA in the cerebrospinal fluid. This is well illustrated in fig 4 where relatively little clot lysis was achieved by tPA treatment. One possible reason for treatment failure is plasminogen deficiency. Andrew et al have shown that neonatal plasma has a plasminogen concentration that is 30 to $50 \%$ of normal adult plasma, and that this is associated with an impaired response to plasminogen activators. ${ }^{31}$ We have shown that cerebrospinal fluid from infants with posthaemorrhagic dilatation contains plasminogen, but at concentrations that are less than $1 \%$ of those of adult plasma. ${ }^{25}$ Such low concentrations of plasminogen must impair the response to tPA. Another possible reason for a poor therapeutic effect is inadequate penetration of tPA either to the arachnoid villi or into the clots. A third possible reason for failure of thrombolysis could be the presence of a fibrinolytic inhibitor. The presence of plasminogen activator inhibitor (PAI-1) has been shown in cerebrospinal fluid in various pathological states, ${ }^{32}$ so this possibility should be investigated.

The most likely reason for treatment failure, however, is that the treatment was started too late when connective tissue organisation of the clots and arachnoiditis had already started. Impressive lysis of the intraventricular clot was achieved (fig 3) but the infant still went on to sustain permanent hydrocephalus. Breakdown products from the intraventricular haemorrhage had probably stimulated a chronic arachnoiditis which continued after the removal of most of the blood clot. The successful animal models of intraventricular fibrinolytic treatment have started within 24 hours of injection of the blood. ${ }^{13-14}$ The successful use of tPA in the ventricular and subarachnoid cerebrospinal fluid of adult patients was 
usually started within three days of the onset of the haemorrhage. ${ }^{15-21}$ Hudgins et al reported four premature infants with posthaemorrhagic hydrocephalus who were treated with intraventricular urokinase, all surviving without shunt surgery. ${ }^{33}$ Hudgins's patients started treatment five to 11 days after the haemorrhage whereas median age at the start of tPA treatment in our study was 15 days (corresponding to about 13 days posthaemorrhage, as most of the haemorrhages were apparent by day 3 ).

\section{MODIFICATIONS TO INTRAVENTRICULAR TPA TREATMENT}

Much has been learnt from this phase I trial, but we conclude that the likely clinical benefit from the current protocol may be too small for such an invasive treatment with a risk of secondary haemorrhage. Possible ways forward are:

-the addition of plasminogen to tPA

-earlier treatment

- further research into the process by which connective tissue is laid down in the subarachnoid space

The combination of early tPA and ventricular drainage seems to us to be theoretically sound, as removal of red cells is just as important as lysis of fibrin. Such an approach has been carried out in adults without secondary haemorrhage being a problem. ${ }^{19-21}$ Making it work consistently in preterm infants is still an unsolved challenge.

This study was supported by grants from the Medical Faculty of the University of Oslo and the Norwegian Association for Cardiovascular Diseases.

1 Volpe JJ. Neurology of the newborn. Philadelphia: WB Saunders, 1995: 403-63.

2 Punt J. Neurosurgical management of hydrocephalus. In Levene MI, Lilford RJ, eds. Fetal and neonatal neurology and neurosurgery. Edinburgh: Churchill Livingstone, 1995 661-6.

3 Mantovani JF, Pasternak JF, Mathew OP, et al. Failure of daily lumbar punctures to prevent the development of hydrocephalus following intraventricular hemorrhage. $f$ Pediatr 1980;97:278-81.

4 Anwar M, Kadam S, Hiatt IM, Hegyi T. Serial lumbar punctures in prevention of posthemorrhagic hydrocephpunctures in prevention of posthemorrhagic hydro
alus in preterm infants. $₹$ Pediatr 1985;107:446-9.

5 Ventriculomegaly Trial Group. Randomised trial of early tapping in neonatal posthaemorrhagic ventricular dilatation. Arch Dis Child 1990;65:3-10.

6 Cowan F, Whitelaw A. Acute effects of acetazolamide on cerebral blood flow velocity and pCO2 in the newborn infant. Acta Paediatrica 1991;80:22-7.

7 Liptak GS, Gellerstedt ME, Klionsky N. Isosorbide in the medical management of hydrocephalus in children with myelodysplasia. Dev Med Child Neurol 1992;34:150-4.

8 Hill A, Shackelford GD, Volpe JJ. A potential mechanism of pathogenesis for early posthemorrhagic hydrocephalus in the premature newborn. Pediatrics 1984; 73:19-21.

9 Larroche JC. Posthaemorrhagic hydrocephalus in infancy. Biol Neonate 1972; 20: 287-99.

10 Whitelaw A. Endogenous fibrinolytic activity in neonatal cerebrospinal fluid. Eur $\mathcal{F}$ Pediatr 1993; 152:928- 0.
11 Whitelaw A, Creighton L, Gaffney P. Fibrinolytic activity in cerebrospinal fluid after intraventricular haemorrhage. Arch Dis Child. 1991;66:808-9.

12 Whitelaw A, Mowinckel M-C, Fellman V, Abildgaard U. Endogenous tissue plasminogen activator in neonatal Endogenous tissue plasminogen activator in neom

13 Pang D, Sclabassi RJ, Horton JA. Lysis of intraventricular clot with urokinase in a canine model. Part 3. Effects of intraventricular urokinase on clot lysis and posthemorrhagic hydrocephalus. Neurosurgery 1986;19:553-72.

14 Brinker T, Seifert V, Dietz H. Subacute hydrocephalus after experimental subarachnoid hemorrhage: its prevention by intrathecal fibrinolysis with recombinant tissue plasminogen activator. Neurosurgery 1992;31:306-12.

15 Findlay JM, Weir B, Kassell NF, Disney LB, Grace MG. Intracisternal recombinant tissue plasminogen activator after aneurusmal subarachnoid hemorrhage. $¥$ Neurosurg after aneurusm

16 Zabramski JM, Spetzler RF, Lee S, Papodopoulos S, Bovill E, Zimmerman RS, et al. Phase 1 trial of tissue plasminowith aneurysmal subarachnoid hemorrhage. $f$ Neurosurg 1991;75:189-96.

17 Stolke D, Seifert V. Single intracisternal bolus of recombinant tissue plasminogen activator: preliminary assessment of efficacy and safety in an open clinical study. Neurosurgery 1992;30:877-81.

18 Mizoi K, Yoshimoto T, Takahashi A, Fujiwara S, Koshi K, Sugawara T. Prospective study on the prevention of cerebral vasospasm by intrathecal fibrinolytic therapy with tissue-type plasminogen activator. $f$ Neurosurg 1993; 78:430-7.

19 Findlay JM, Grace MG, Weir BKA. Treatment of intraventricular hematoma with tissue plasminogen activator. $\mathrm{Neu}$ rosurgery 1993;32:941-7.

20 Mayfrank L, Lippitz B, Groth M, Bertanffy H, Gilsbach JM. Effect of recombinant tussue plasminogen activator on clot lysis and ventricular dilatation in the treatment of severe intraventricular haemorrhage. Acta Neurochirurgica 1993;122:32-8.

21 Rohde V, Schaller C, Hassler WE. Intraventricular recombinant tissue plasminogen activator for lysis of intraventricular haemorrhage. $\mathcal{F}$ Neurol Neurosurg Psychiatry 1995; 58: 447-51.

22 Stewart GT. Fibrinolytic therapy in meningitis and ventriculitis. $\mathcal{F}$ Clin Pathol 1964; 17:355-9.

23 Whitelaw A, Rivers R, Creighton L, Gaffney P. Low dose intraventricular fibrinolytic therapy to prevent posthaemintraventricular fibrinolytic therapy to prevent posthaem-
orrhagic hydrocephalus. Arch Dis Child. 1992;67:F12-14

24 Marder VJ, Sherry S. Thrombolytic therapy: current status. Part 1. N Engl ₹ Med 1988; 318: 1512- 20.

25 Whitelaw A, Mowinckel M-C, Abildgaard U. Low levels of plasminogen in cerebrospinal fluid after intraventricular haemorrhage: a limiting factor for clot lysis? Acta Paediat 1995:84:933-6.

26 Levene MI, Measurement of the growth of the lateral ventricles in preterm infants with real time ultrasound. ventricles in preterm infants
Arch Dis Child 1981;56:900-4.

27 Kaiser A, Whitelaw A. Normal cerebrospinal fluid pressure in the newborn. Neuropediatrics 1986;17:100-2.

28 Tanswell $P$, Tebbe U, Neuhaus KL, Glasle-Schwarz L Wojcik J, Seifried E. Pharmacokinetics and fibrin specificity of alteplase during accelerated infusions in acute myo cardial infarction. $\mathcal{F}$ Am Coll Cardiol 1992;19:1071-5.

29 Papile LA, Burstein J, Burstein J, Koffler H. Incidence and evolution of subependymal and intraventricular hemorrhage: a study of infants with birth weights under $1500 \mathrm{gm}$ f Pediatr 1978; 92: 529-34.

30 Benet LZ, Sheiner LB. Pharmacokinetics: the dynamics of drug absorption, distribution and elimination. In : Gilman AG, Goodman LS, Rall TW, Murad F, eds. The pharmacoAG, Goodman LS, Rall TW, Murad F, eds.The pharmaco3-34.

31 Andrew M, Brooker L, Leaker M, Paes B, Weitz J. Fibrin clot lysis by thrombolytic agents is impaired in newborns due to a low plasminogen concentration. Thromb Haemostas 1992;68:325-30.

32 Sutton R, Keohane ME, Van den Berg, Gonias SL. Plasminogen activator inhibitor -1 in the cerebrospinal fluid as an index of neurological disease. Blood Coag Fibrin 1994 5: $167-1$.

33 Hudgins RJ, Boydston WR, Hudgins PA, Adler SR Treatment of intraventricular hemorrhage in the premature infant with urokinase. A preliminary report. Pediatr Neurosurg 1994;20:190-7. 